\title{
Optimal management of cancer anorexia-cachexia syndrome
}

This article was published in the following Dove Press journal:

Cancer Management and Research

21 January 2010

Number of times this article has been viewed

\section{Josep M Argilés \\ Mireia Olivan \\ Sílvia Busquets \\ Francisco Javier López- \\ Soriano}

Departament de Bioquímica i Biologia Molecular, Universitat de Barcelona, Barcelona, Spain
Correspondence: Josep M Argilés Cancer Research Group, Departament de Bioquímica i Biologia Molecular, Facultat de Biologia, Universitat de Barcelona, Diagonal 645, 08028-Barcelona, Spain Tel +34934021002

Fax +349340 21559

Email jargiles@ub.edu
Abstract: According to a recent consensus, cachexia is a complex metabolic syndrome associated with underlying illness and characterized by loss of muscle with or without loss of fat mass. The prominent clinical feature of cachexia is weight loss. Cachexia occurs in the majority of cancer patients before death and it is responsible for the deaths of $22 \%$ of cancer patients. Although bodyweight is the most important endpoint of any cachexia treatment, body composition, physical performance and quality of life should be monitored. From the results presented here, one can speculate that a single therapy may not be completely successful in the treatment of cachexia. From this point of view, treatments involving different combinations are more likely to be successful. The objectives of any therapeutic combination are two-fold: an anticatabolic aim directed towards both fat and muscle catabolism and an anabolic objective leading to the synthesis of macromolecules such as contractile proteins.

Keywords: wasting, cancer, anorexia, nutraceuticals, drugs

\section{Introduction}

\section{A definition of cachexia}

Perhaps the most common manifestation of severe disease, such as acquired immunodeficiency syndrome (AIDS), chronic heart failure (CHF) and cancer, is the development of cachexia. Although there is no single, generally agreed upon, definition of cachexia, a recent consensus states that "cachexia is a complex metabolic syndrome associated with underlying illness and characterized by loss of muscle with or without loss of fat mass. The prominent clinical feature of cachexia is weight loss in adults (corrected for fluid retention) or growth failure in children (excluding endocrine disorders). Anorexia, inflammation, insulin resistance and increased muscle protein breakdown are frequently associated with cachexia". Cachexia is distinct from starvation, age-related loss of muscle mass, primary depression, malabsorption and hyperthyroidism and is associated with increased morbidity. ${ }^{1}$ Cachexia occurs in the majority of cancer patients before death and, according to Warren, it is responsible for the deaths of $22 \%$ of cancer patients. ${ }^{2}$ Interestingly, in studies performed before the era of highly active antiretroviral therapy, estimates of prevalence of wasting as the first AIDS-defining diagnosis ranged up to $31 \% .{ }^{3}$ Fatigue, as a result of muscle wasting, is an extremely common symptom in cardiac cachexia patients. This condition is observed among a high percentage of chronic heart failure patients. ${ }^{4}$ In cancer, cachexia is a multi-organ syndrome characterized by weight loss (at least 5\%), muscle and adipose tissue wasting and inflammation - often associated with anorexia. The abnormalities 
associated with cachexia include alterations in carbohydrate, lipid and protein metabolism..$^{5}$ These metabolic abnormalities are caused by both humoral inflammatory mediators (such as cytokines) and of tumor origin.

Although a plethora of treatments for the cachectic syndrome have been proposed, unfortunately, not a single one is completely satisfactory. When treating weight loss associated with cachexia, two targets have to be considered. Firstly, food intake should be controlled with the aim of reducing anorexia (Figure 1). In addition, contributing factors to decreased food intake could be assessed and treated. This clearly constitutes the first aim of the therapy of wasting. Secondly, providing complete nutritional requirements by means of total parenteral nutrition does not abrogate the weight loss. It is thus clear that, in addition to controlling food intake, the metabolic disturbances associated with tumor burden contribute most importantly to the appearance of cachexia. Therefore, neutralizing the metabolic alterations which include abnormal carbohydrate metabolism, lipid mobilization, hepatic protein metabolism and, above all,

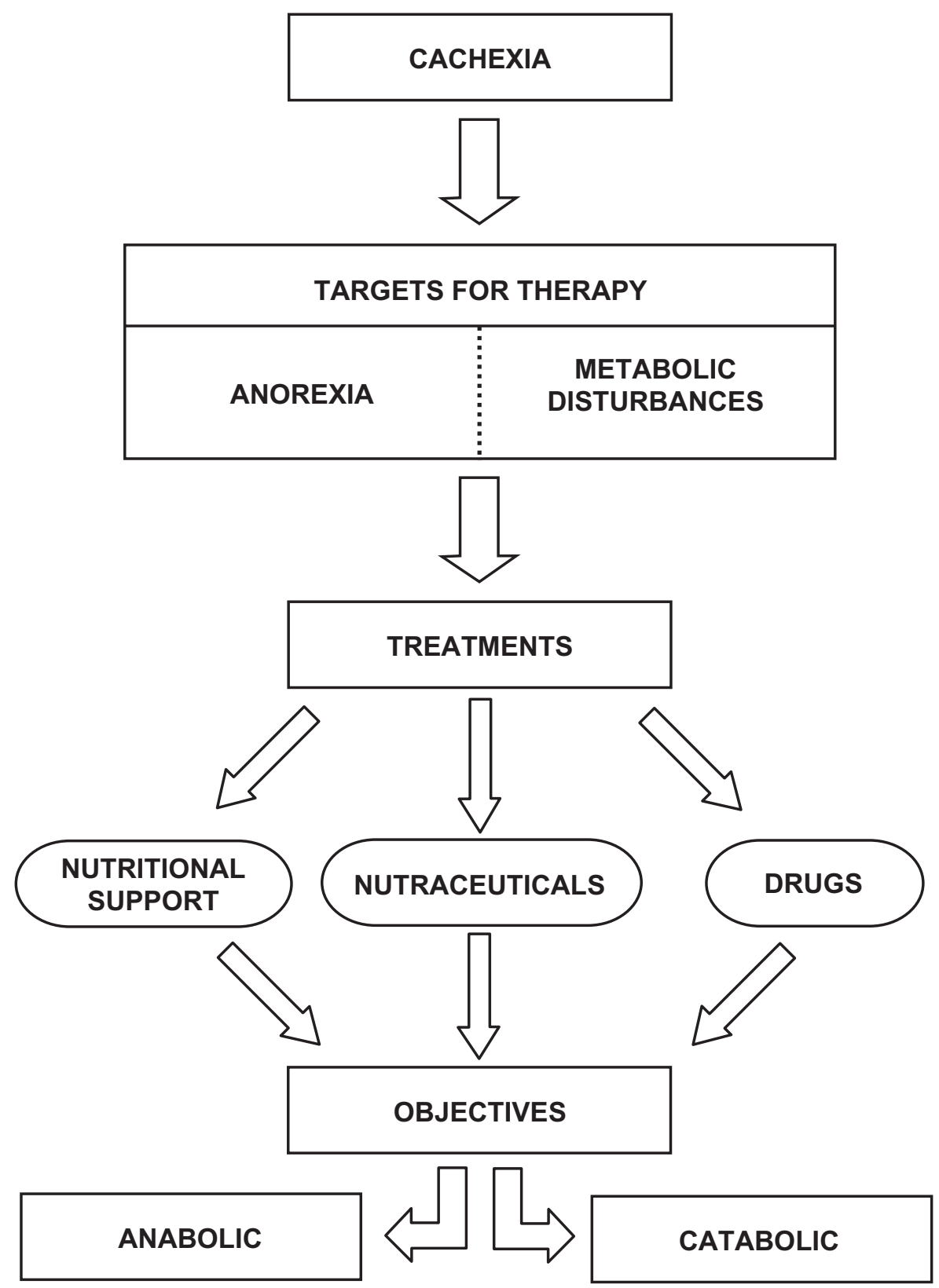

Figure I Therapeutic targets for cancer cachexia. There are different therapeutic approaches to fight anorexia and metabolic disturbances based in the combination of nutritional support, nutraceuticals and specific drugs. The objectives for cachexia treatment are two: anticatabolic (directed towards both fat and muscle) and anabolic (leading to the synthesis of macromolecules). 
alterations in the rate of skeletal muscle protein breakdown is of paramount importance, 6,7 (Figure 1).

There are novel approaches for reaching the targets referred to above in addition to nutritional support. The use of the nutraceuticals has led to interesting results. ${ }^{8,9}$ In order to reverse metabolic disturbances, many drugs have been proposed and used in clinical trials, while others are still under investigation using experimental animals. The best treatment of the cachectic syndrome is most likely to be a multifactorial approach. In relation to this, the combination of nutritional support with different nutraceuticals has already been reported to be relatively successful. ${ }^{10} \mathrm{~A}$ combination of nutritional support and nutraceuticals with specific drugs may lead to optimal results. There are two objectives of any therapeutic combination: an anti-catabolic aim directed towards both fat and muscle catabolism, and an anabolic objective leading to the synthesis of macromolecules such as contractile proteins (Figure 1).

\section{Assessing endpoints}

Independent of the treatment, the monitoring of cachexia is a key issue during therapy. Different parameters can be used but, inevitably, they rely on the targets mentioned before. In relation to anorexia, food intake, intestinal absorption, delayed gastric emptying, and dysphagia constitute important parameters to be monitored. Often, the treatment of the tumor also causes alterations in both the taste and smell of foods; therefore, this should also be taken into consideration. In addition, metabolic alterations are varied and complex. Assessment of energy expenditure (both resting and total), inflammation (C-reactive protein), glucose intolerance, fat mobilization (lipolysis) and protein breakdown are important endpoints and should ideally be monitored, (Figure 2).

Although bodyweight is the most important endpoint of any cachexia treatment, body composition (lean body mass, fat mass, water) should be analyzed by means of BIA (body impedance analysis), DEXA (dual-energy X-ray absorptiometry) or CT-scanning (computer tomography), since an increase in bodyweight based on fat or water-without an increase in lean body mass - may not be relevant (Figure 2). It is also important to also include measurements of physical performance (eg, the monitoring of total activity and grip force evaluation). Indeed, physical performance is linked with quality of life (that can be estimated through the use of different questionnaires), one of the most important endpoints of any cachexia therapy. Finally in relation to cancer treatments, survival is an endpoint that reflects the impact of any cachexia therapy $^{11}$ (Figure 2).

\section{Approaches to the treatment of cachexia}

Several pharmacological and nutritional approaches have been used (Table 1). Bearing in mind that both anorexia and metabolic disturbances are involved, the development of different therapeutic strategies has focused on the following two factors.

\section{Improving appetite}

\section{Progesterone derivates}

Megestrol acetate and medroxyprogesterone are synthetic, orally active derivatives of the naturally occurring hormone progesterone. In humans these compounds have been found to improve appetite, caloric intake and nutritional status in several clinical trials. ${ }^{12-14}$ The human trials involving progesterone derivatives have on the whole demonstrated, with few exceptions, a favorable effect on appetite and weight gain, which is a positive value for body image. However, this has been mainly attributed to an increased fat mass, not to muscle mass. ${ }^{15}$ Oral suspension of the progestational agent may be particularly useful in patients with advanced disease, where taking larger amounts of pills may lead to the decrease of patient compliance. Recent data by Tomíska et al showed that an oral megestrol acetate suspension given to patients with advanced cancer and additionally suffering from anorexia resulted in an improvement of appetite and quality of life. ${ }^{16}$ A recent meta-analysis concludes that megestrol acetate is able to reduce the symptoms of cachexia with no effect on survival or quality of life. ${ }^{17}$

\section{Cannabinoids}

Cannabinoids, which are present in marijuana, have a definitive effect on weight gain and have been used to increase food intake in cancer patients. The mechanism by which cannabinoids exert their effects has yet to be clarified. It was postulated that they may act via endorphin receptors, or by inhibiting prostaglandin synthesis. ${ }^{18}$ Other reports suggest that the marijuana derivative may act by inhibiting cytokine production and/or secretion. ${ }^{19,20} \mathrm{~A}$ recent clinical trial, however, has shown very little efficacy of either orally administered cannabinoid extract or $\Delta 9$-tetrahydrocannabinol in treating patients with cancer-related anorexia-cachexia syndrome. ${ }^{21}$

\section{Cyproheptadine}

Considerable evidence, both in humans and experimental animals, suggests that anorexia may be mediated by an increased serotonergic activity in the brain. ${ }^{22}$ Taking this into consideration, attempts to block serotonin activity during 


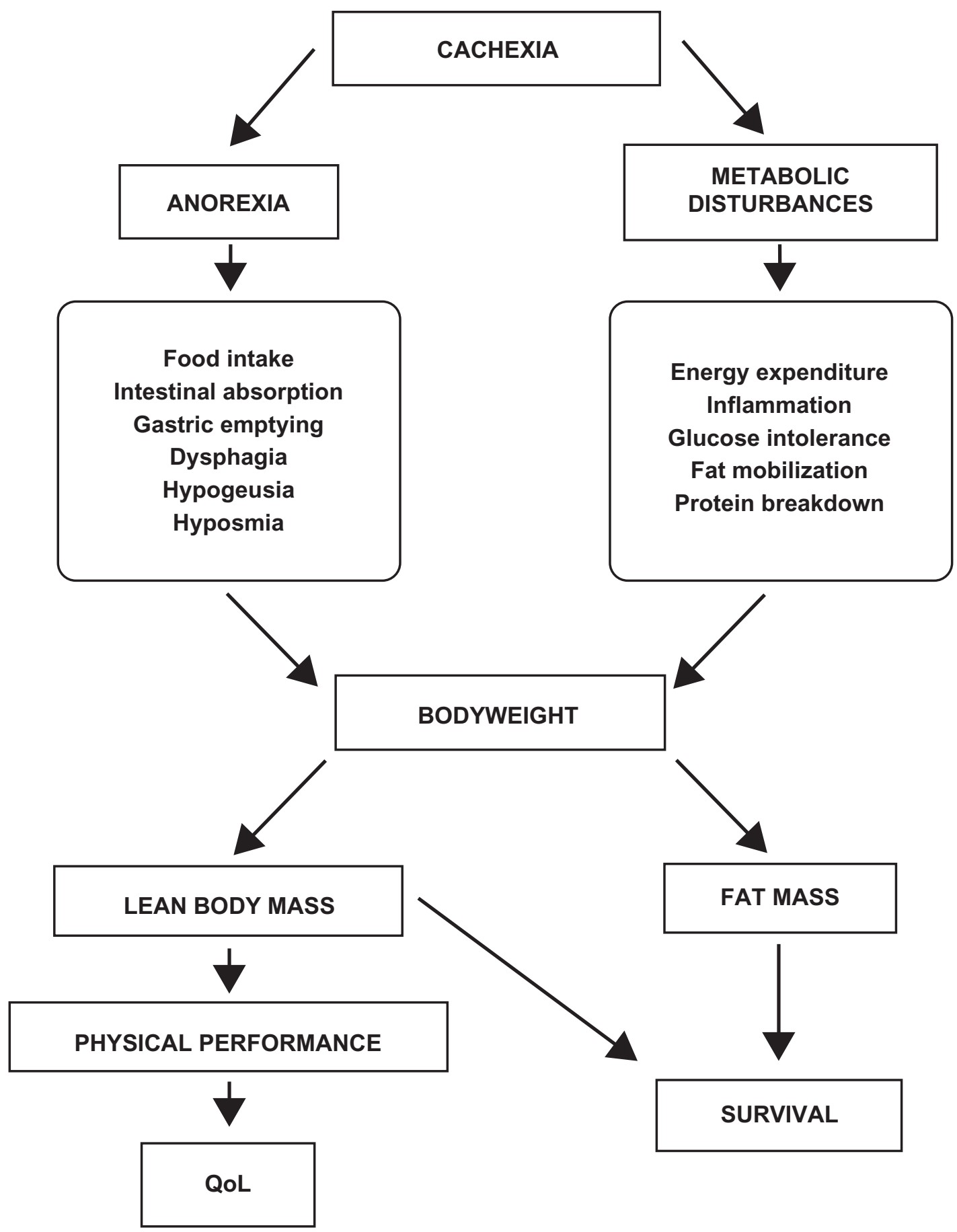

Figure 2 Cachexia endpoints. The monitoring of cachexia is a key issue during therapy. Different parameters in relation with anorexia and metabolic disturbances should be taken into consideration.Although bodyweight is the most important endpoint, body composition, physical performance and survival, which reflect the impact of the treatment, should also be taken into consideration and analyzed.

Abbreviation: QoL, quality of life.

cancer cachexia have involved the use of cyproheptadine, a serotonin antagonist with antihistaminic properties, usually used for the treatment of allergies. Although initial clinical data suggested that it had appetite and weight-enhancing effects in both patients with cancer-related cachexia and without; however, it did not prevent progressive weight loss in patients with advanced malignant disease..$^{23} \mathrm{~A}$ recent pilot study, however, demonstrates that cyproheptadine treatment was able to enhance bodyweight in children with cachexia. ${ }^{24}$ Future clinical trials with other anti-serotonergic drugs are necessary to define the role of the serotonergic system in the development of cancer cachexia. 
Table I Efficiency of the different anti-cachexia treatments

\begin{tabular}{lll}
\hline Drug & $\begin{array}{l}\text { Experimental } \\
\text { animals }\end{array}$ & Humans \\
\hline Progesterone derivatives & ++ & ++ \\
Cannabinoids & ++ & + \\
Cyproheptadine & + & + \\
Corticosteroids & - & - \\
Ghrelin & ++ & ++ \\
Pentoxifylline & ++ & $?$ \\
Thalidomide & + & + \\
Anti-cytokine antibodies & +++ & - \\
and soluble receptors & & $?$ \\
Anti-inflammatory cytokines & ++ & ++ \\
Anabolic steroids & ++ & $?$ \\
32-adrenergic agonists & +++ & ++ \\
$\omega$-3-fatty acids & ++ & + \\
Prostaglandin inhibitors & ++ & $?$ \\
ACE inhibitors & ++ & ++ \\
EPO & $?$ & + \\
ATP & $?$ & + \\
Creatine & + & + \\
Amino acids & + & + \\
Proteasome inhibitors & + & + \\
\hline Da rer & + & + \\
\hline
\end{tabular}

Data refer to experimental and clinical trials. +, slight beneficial effect. ++ relatively good results. ++, satisfactory treatment. -, unsuccessful trial. ?, unknown. Table adapted from Argilés et al.

Abbreviations: ACE, angiotensin-converting enzyme; EPO, erythropoietin; ATP, adenosine triphosphate.

\section{Corticosteroids}

This group of hormones was one of the first pharmacological approaches for the treatment of cancer related anorexia. Indeed, they have been used to increase food intake in cancer patients and a number of uncontrolled studies have shown that some of the symptoms in cancer patients (such as anorexia and asthenia) can be partially mitigated by corticosteroids treatment, giving the patient an increased sensation of well being. Dexamethasone significantly decreases appetite loss and weight loss in lung cancer patients treated with chemotherapy, although it has little influence on appetite improvement and weight gain..$^{25}$ Although corticosteroid treatment has been associated with low toxicity in several trials, prolonged treatment seems to lead to weakness, delirium, osteoporosis and immunosuppression, all of which are commonly present in advanced cancer patients. ${ }^{26}$

However, corticosteroids do seem to improve the quality of life of terminal cancer patients and can be used as palliative therapy. Unfortunately, corticosteroid treatment does not seem to have any significant effects in the reduction of mortality. ${ }^{27}$

\section{Orexigenic and anorexigenic mediators: ghrelin}

The orexigenic mediator, ghrelin $(\mathrm{GH})$ - a novel endogenous ligand for the growth hormone secretagogue receptor - has recently been reported as having a key role in increasing appetite and therefore food intake. In addition to increasing food intake, the peptide inhibits leptin and proinflammatory cytokines expression. ${ }^{28}$ An experimental study has shown that repeated administration of ghrelin improves cardiac structure and function, and attenuates the development of cardiac cachexia in CHF. These results suggest that ghrelin has cardiovascular effects and regulates energy metabolism through GH-dependent and GH-independent mechanisms. ${ }^{29}$ Therefore the administration of ghrelin may be a new therapeutic strategy for the treatment of severe CHF. A phase I randomized, placebo-controlled, double-blind, multiple-dose study using an oral ghrelin mimetic demonstrated an increase of bodyweight in healthy volunteers. ${ }^{30}$

\section{Melanocortin antagonists}

Melanocortin (MC4) receptor is involved in the anorexigenic cascade, modulating food intake by two different mechanisms which are both leptin-dependent and leptinindependent. ${ }^{31}$ The use of MC4 antagonists has proved to be effective in preventing anorexia, loss of lean body mass and basal energy expenditure in experimental animals suffering from cachexia. ${ }^{32,33}$ However, no data on human subjects are available and future clinical trials may prove the efficacy of this type of antagonist in the treatment of human cachexia.

\section{Neutralizing metabolic disturbances Cytokines-based therapeutic approaches}

Cytokines act on multiple target sites, such as bone marrow, myocytes, hepatocytes, adipocytes, endothelial cells and neurons, where they produce a complex cascade of biological responses that lead to the wasting associated with cachexia. The cytokines that have been implicated in this cachectic response are tumor necrosis factor (TNF)- $\alpha$, interleukin (IL)-1, IL-6 and interferon- $\gamma$ (IFN- $\gamma$ ). Interestingly, these cytokines share the same metabolic effects, and their activities are closely interrelated. In many cases, these cytokines exhibit synergic effects when administered together. ${ }^{34}$ Therefore therapeutic strategies have been based on either blocking their synthesis or their action. ${ }^{35}$ 


\section{Pentoxifylline}

Pentoxifylline, a methylxanthine derivative, is a phosphodiesterase inhibitor that inhibits TNF synthesis by decreasing gene transcription. This drug was originally used for the treatment of various types of vascular insufficiency because of its hemorheological activity, thought to be based on its ability to reduce blood viscosity and increase the filterability of blood cells. Although several studies using animal models suggest that pentoxifylline is able to decrease the cytokine induced toxicity of antineoplastic agents while preserving anti-tumor treatment efficacy. ${ }^{36}$ Clinical studies have shown that the drug failed to improve appetite or increase the weight of cachectic patients, ${ }^{37}$ and patients in the study frequently reported gastrointestinal side effects. However, the reported clinical trials have been relatively small and therefore larger randomized studies are necessary to assess the efficacy of pentoxifylline in the treatment of cancer cachexia.

\section{Thalidomide}

Thalidomide ( $\alpha$-N-phthalimidoglutaramide) is a drug that in the past has been, unfortunately, associated with tragedy. Indeed, its use as a sedative in pregnant women caused over 10,000 cases of severe malformations in newborn children. However, a certain revival has improved the drug's profile, since it has been demonstrated to suppress TNF-alpha production in monocytes in vitro and to normalize elevated TNF-alpha levels in vivo. ${ }^{38,39} \mathrm{~A}$ randomized placebocontrolled trial in patients with cancer cachexia showed that the drug was well-tolerated and effective at attenuating loss of weight and lean body mass in patients with advanced pancreatic cancer, although no improvement in survival was obtained. ${ }^{40}$

\section{Antibodies and soluble receptors}

The use of anti-cytokine antibodies (either mono or polyclonal) and cytokine receptor antagonists or soluble receptors has led to some interesting results. In rats bearing the Yoshida AH-130 ascites hepatoma (a highly cachectic tumor) antiTNF therapy resulted in a partial reversal of the abnormalities associated with both lipid and protein metabolism..$^{41,42}$ In humans however, clinical trials using anti-TNF treatment has led to poor results in reversing protein catabolism associated with sepsis and cancer cachexia. ${ }^{43}$ Concerning IL-6, experimental models have proved that the use of antibodies is highly effective in preventing tumor-induced waste. ${ }^{44}$ Strassman et al have demonstrated that the experimental drug suramine (which prevents the binding of IL-6 to its cell surface receptor, as demonstrated by radioreceptor-binding assay and affinity binding experiments) partially blocks (up to $60 \%$ ) the catabolic effects associated with the growth of the colon-26 adenocarcinoma in mice..$^{45}$

Concerning other cytokines, anti-IFN- $\gamma$ therapy has also been effective in reverting cachexia in mice bearing the Lewis lung carcinoma, although there is a paucity of clinical data ${ }^{46}$ Additionally blocking IL-1 actions by means of the IL-1 receptor antagonist (IL-1 ra) in tumor-bearing rats had no effect on either bodyweight or reversal of metabolic changes ${ }^{47} \mathrm{~A}$ similar approach is the use of anti-cytokine strategies such as etanercept (fusion protein directed against p75 TNF receptor). Monk et al showed in a clinical pilot study with several advanced malignancies that patients treated with etanercept combined with an antitumor agent (docetaxel) had less fatigue and improved tolerability of the antitumoral treatment. However, the routine use of anti-cytokine antibodies is, at present, too expensive due to the fact that this type of therapy requires a very large number of antibody molecules in order to block cytokine action completely. ${ }^{48}$

\section{Anti-inflammatory/anabolic cytokines}

The degree of the cachectic syndrome is dependent not only on the production of the cytokines known as catabolic proinflammatory cytokines, but also on the so-called antiinflammatory cytokines, such as IL-4, IL-10, and IL-12. Interleukin-15 has been reported to be an anabolic factor for skeletal muscle. ${ }^{49}$ This cytokine is able to decrease protein degradation, decrease the rate of DNA fragmentation and increase UCP3 expression in skeletal muscle, these being the most important trends associated with muscle wasting during cancer cachexia. ${ }^{50,51}$ In vitro experiments carried out using both isolated incubated muscle and muscle cells in culture corroborate the in vivo observations indicating a direct action of the cytokine upon skeletal muscle..$^{52}$ Although no clinical data are available, treatment of cachectic experimental animals with IL-15 leads to an improvement of muscle mass and performance..$^{50}$

\section{Other therapeutic approaches}

\section{Anabolic steroids}

Although treatment with derivatives of gonadal steroids can have significant side effects, such as masculinization, fluid retention and hepatic toxicity, they promote protein accumulation and could be used to counteract the progressive nitrogen loss associated with cachexia. Recent data from a double-blind placebo-controlled trial suggest that nandrolone decanoate is effective in the treatment of cachectic AIDS patients, increasing lean body mass, 
quality of life and decreasing anti-AIDS treatment toxicity. ${ }^{53}$ A recent clinical trial using a non-steroidal selective androgen receptor modulator (SARM) carried out to increase lean body mass and improve physical performance in healthy elderly subjects was successful and the potential activity of this class of drugs should be taken into consideration for cancer cachexia. ${ }^{54}$

\section{$\beta 2$-adrenergic agonists}

These molecules are potentially very interesting since they have important effects on protein metabolism in skeletal muscle, favoring protein deposition. Apart from the older $\beta 2$-adrenergic agonists, such as clenbuterol, the interest has been recently focused on newer drugs such as formoterol. In particular, the use of this $\beta 2$-adrenergic agonist in experimental animals has proved to be useful in reversing muscle wasting associated with cancer. ${ }^{55}$ In addition to its relatively low toxicity, formoterol is able to reverse the muscle-wasting process. The anti-wasting effects of the drug were based on both an activation of the rate of protein synthesis and an inhibition of the rate of muscle proteolysis. Northern blot analysis revealed that formoterol treatment resulted in a decrease in the mRNA content of ubiquitin and proteasome subunits in gastrocnemius muscles. This, together with the decreased proteasome activity observed, suggested that the main antiproteolytic action of the drug may be based on inhibition of the ATP-ubiquitin-dependent proteolytic system. ${ }^{55}$ Interestingly, the $\beta 2$-agonist was also able to diminish the increased rate of muscle apoptosis present in tumor-bearing animals, and was able to facilitate muscle regeneration by stimulating satellite cells proliferation. The results indicate that formoterol exerted a selective, powerfully protective action on heart and skeletal muscle by antagonizing the enhanced protein degradation that characterizes cancer cachexia. Formoterol may potentially be a therapeutic tool in pathological states wherein muscle protein hypercatabolism is a crucial feature, such as cancer cachexia or other wasting diseases. ${ }^{55}$

\section{$\beta$-blockers}

These drugs can reduce body energy expenditure and improve efficiency of substrate utilization. Interestingly, patients with CHF treated with $\beta$-blockers can increase total body fat mass and partially reverse cachexia. ${ }^{56}$

\section{$\omega$-3-fatty acids}

$\omega$-3-Polyunsaturated fatty acids ( $\omega$-3-PUFA), present in large amounts in fish oil, have been proposed to be very active in reducing either tumor growth or the associated tissue wasting, particularly that of the adipose mass. ${ }^{57,58}$ Interest in $\omega$-3-PUFA was originated from the observation that populations consuming a diet rich in such constituents showed the lowest incidence of certain types of cancer. An improvement in the lean body mass and quality of life was observed in a randomized double-blind trial using a protein and energy dense $\omega$-3-fatty acid-enriched oral supplement, provided that its consumption was equal to or in excess of $2.2 \mathrm{~g}$ eicosapentaenoic acid (EPA)/day. ${ }^{59}$ However, recent data arising from a large multicentre double-blind placebocontrolled trial, indicates that EPA administration alone is not successful in the treatment of weight loss in patients with advanced gastrointestinal or lung cancer. ${ }^{60}$ Moreover, a recent meta-analysis based on five trials concluded that there were insufficient data to establish whether oral EPA was better than placebo. Comparisons of EPA combined with a protein energy supplementation versus a protein energy supplementation without EPA, in the presence of an appetite stimulant $\left(\right.$ Megace $\left.^{\circledR}\right)$ provided no evidence that EPA improves symptoms associated with the cachexia syndrome often seen in patients with advanced cancer. ${ }^{61} \mathrm{In}$ CHF, fish oils produce anti-inflammatory effects by decreasing TNF- $\alpha$ production and improve bodyweight. ${ }^{62}$ However, recent trials support the benefits of fish oil therapy for cachexia. Guarcello and colleagues used EPA-enriched oral nutrition in patients with lung cancer reported a positive effects on bodyweight and quality of life. ${ }^{63}$ A similar study by Read et al suggests that nutrition intervention with EPA improves bodyweight and reduces inflammation. ${ }^{64}$ Similarly, a double-blind randomized trial using $\omega$-3-fatty acids in non-small cell lung carcinoma, reported increased bodyweight in comparison with the control subjects receiving standard nutrition supplementation. ${ }^{65}$ In children receiving chemotherapy the use of a protein and energy dense EPA-containing supplement resulted in an improvement of both bodyweight and body mass index. ${ }^{66}$ Ryan and colleagues in a double-blind randomized trial, used enteral nutrition based EPA in patients with esophageal cancer surgery; the results demonstrated beneficial effects on bodyweight ${ }^{67}$ Finally, the combination of $\omega$-3-fatty acids with the Cox-2 inhibitor celecoxib reduced inflammation and increased muscle strength in cachectic cancer patients. ${ }^{68}$

\section{Amino acids}

Peripheral muscle proteolysis, as occurs in cancer cachexia, serves to mobilize amino acids required for the synthesis of liver and tumor protein. ${ }^{69}$ Therefore, the administration of exogenous amino acids may theoretically serve as a protein-sparing metabolic fuel by providing substrates for 
both muscle metabolism and gluconeogenesis. Therefore branched-chain amino acids ([BCAA] such as leucine, isoleucine and valine) have been used in parenteral nutrition with the aim of improving nitrogen balance and particularly, muscle protein metabolism. Tayek and colleagues in a prospective, randomized, crossover trial involving patients with advanced intra-abdominal adenocarcinoma, concluded that BCAA-enriched total parenteral nutrition resulted in improved protein accretion and albumin synthesis. ${ }^{70}$ Similarly, studies with tumor-bearing animals show that high BCAA concentrations in total parenteral nutrition have beneficial effects on host protein metabolism. ${ }^{71}$ Cangiano et al have proposed that BCAA administration would also serve to counteract the anorexia associated with tumor growth. ${ }^{72}$ The authors postulated that increased hypothalamic serotonergic activity is one of the pathogenic mechanisms leading to the development of cancer anorexia. In addition, data from the authors' own laboratory show that BCAAs (in particular leucine) act by decreasing skeletal muscle protein degradation, mainly by inhibiting the activation of the ubiquitin proteolytic system. ${ }^{73}$ Free tryptophan (the precursor of brain serotonin) is increased during cancer and BCAA may act by competing for the same transport system as tryptophan across the blood-brain barrier. ${ }^{74,75}$ This hypothesis has been tested in anorectic cancer patients receiving an oral supplementation of BCAA with encouraging results, as the treatment decreased the severity of the anorexia in the treated patients. ${ }^{73}$

Glutamine-enriched solutions have also been used in total parenteral nutrition with the aim of enhancing immunoregulation of tumor growth, and compensating for the uptake of the amino acid by the tumor. ${ }^{76}$ Indeed, tumor cells are major glutamine consumers (for both protein synthesis and oxidation) and, therefore, lead to host glutamine depletion, ${ }^{77,78}$ which results in a decreased host immune response and gastrointestinal mucosal integrity. ${ }^{76}$ In patients undergoing bone marrow transplantation for hematological malignancies, glutamine supplementation was found to be beneficial, improving nitrogen balance and diminishing the incidence of clinical infection as compared with the standard parenteral nutrition therapy. ${ }^{79}$ It could be argued that glutamine supplementation may facilitate tumor growth as it is one of the preferred substrates for fast-growing tumors. However, evidence obtained in experimental models demonstrates that glutamine supplementation improves the tumoricidal effectiveness of methotrexate while reducing its toxicity. ${ }^{80}$ As Laviano and colleagues suggest, this could be due to the increased number of glutamine-induced tumor cells in the S-phase of the cell cycle, during which they are more susceptible to chemotherapy. ${ }^{81}$ The combination of glutamine, arginine and $\beta$-hydroxy- $\beta$-methylbutyrate - a leucine metabolite - has been proven to be effective in increasing free fatty mass in advanced cancer patients. ${ }^{82}$

Increasing evidence suggests that an abnormal cysteine and glutathione metabolism plays a decisive role in the development of catabolic conditions and associated immunological dysfunctions. ${ }^{83}$ Indeed, the increased glycolytic activity and lactate production that takes place during cancer causes an acidification of the muscle cells that may result in a decreased transport of glutamate and, in an impaired glutathione metabolism. ${ }^{6,83}$ The acidification is aggravated by the fact that the temporary increase of intracellular pyruvate causes an increased rate of cysteine/ pyruvate transaminase and, consequently, an increased cysteine degradation into sulfate and protons. ${ }^{83}$ Increased intracellular sulfate levels have indeed been found in skeletal muscle of tumor-bearing mice. ${ }^{84}$ This was associated with a decrease of the glutathione level in the skeletal muscle tissue, thus indicating that the cysteine catabolism was increased at the expense of glutathione biosynthesis at this time. ${ }^{83}$ With this in mind, Dröge and colleagues suggest that $N$-acetylcysteine can be used to increase the availability of cysteine in the treatment of catabolic states such as cancer cachexia. ${ }^{83}$

\section{Prostaglandin and nitric oxide inhibitors}

The effects of prostaglandins on cell growth have been studied both in vitro and in vivo, ${ }^{85,86}$ and it has been proposed that cell growth may be controlled by the interconversion of different types of prostaglandins. Indeed, large amounts of these compounds are found both in tumor tissue and plasma from cancer patients. ${ }^{87}$ Taking this into consideration, several studies have examined the role of cyclooxygenase (Cox) inhibitors on tumor growth and cachexia. The results obtained are clearly contradictory. Whereas Homem-deBittencourt et al reported that indomethacin, ibuprofen and aspirin markedly inhibit tumor growth and reduce anorexia in rats bearing the Walker-256 carcinosarcoma, ${ }^{88}$ McCarthy and Daun (using the same rat tumor model) also reported a decrease in tumor weight, but this was not associated with a reduction of anorexia or loss in bodyweight. ${ }^{89}$ Hussey and Tisdale have studied the effects of the Cox-2 inhibitor meloxican on tumor growth and cachexia in the murine adenocarcinoma MAC16. The results suggest that the inhibitor is able to effectively attenuate cachexia, possibly by exercising a direct effect on skeletal muscle 
protein degradation. ${ }^{90}$ Results from a recent pilot study using celecoxib in cancer also showed that the Cox-2 inhibitors improved weight and quality of life scores. ${ }^{91}$

Inhibition of nitric oxide production by specific blockade of the synthase (NOS) resulted in decreased muscle wasting in a model of cachexia. Interestingly, the decrease in bodyweight, the muscle wasting and skeletal muscle molecular abnormalities were prevented by the use of both $N$-nitroL-arginine (a NOS inhibitor) and antioxidants..$^{92}$ Further studies with other tumor models are needed before any serious conclusions can be drawn about the beneficial effects of prostaglandin inhibitors on cancer cachexia.

\section{Angiotensin-converting enzyme inhibitors}

In $\mathrm{CHF}$, inhibition of the angiotensin-converting enzyme (ACE) by administration of enalapril reduces the risk of weight loss and it is linked to improved survival. ${ }^{93}$ Preliminary results demonstrate increased subcutaneous fat (increased skin fold thickness) and greater muscle bulk (increased mid-upper arm and tight circumferences), together with a significant elevation in plasma albumin and hematocrit. ${ }^{94}$ ACE inhibitors, like captopril, seem to act by decreasing the production of TNF- $\alpha$ by mononuclear cells, suggesting a mechanism that accounts for the beneficial effects (related to bodyweight) observed in heart failure patients. ${ }^{95}$ The highly lipophilic ACE inhibitor imidapril attenuated the development of weight loss in mice bearing the MAC16 tumor, suggesting that angiotensin II may play a role in the development of cachexia in this model. ${ }^{96}$

\section{Anti-anemic drugs}

The administration of erythropoietin (EPO) to cancer patients results in a clinical benefit in patients with normal or subnormal hemoglobin levels. ${ }^{97}$ Interestingly Kanzaki and colleagues have shown that in tumor-bearing mice the positive therapeutic effects of EPO in cancer cachexia are due not only to improved metabolic and exercise capacity - via an increased erythrocyte count - together with the attenuation of cachectic manifestations through the decreased production of the cachexia-inducing cytokines. ${ }^{98}$

\section{ATP and creatine}

During catabolic conditions, as in illness, energy demands often increase and the maintenance of bodyweight becomes a balance between such demands and energy supplements. It is for this reason that administration of ATP, a directly hydrolyzable source of energy, could potentially tip the balance towards weight gain and preservation of lean body mass. Several clinical data support this observation..$^{99,100}$ Using a similar principle, perhaps more directly linked with skeletal muscle, creatine administration may result in an increase in skeletal muscle phosphocreatine content, which may protect the tissue during catabolic conditions. This new therapeutic approach merits further attention.

\section{Proteolytic system inhibitors}

Enhanced protein degradation in skeletal muscle during cachexia involves activation of the ubiquitin/proteasome system in muscle. Therefore, inhibitors of this proteolytic system such as peptide aldehyde, lactacystin and $\beta$-lactone which can effectively block up to $90 \%$ of the degradation of both normal and short-lived cellular proteins - are potential drugs for the treatment of muscle wasting. ${ }^{101}$ However, the toxicity of such compounds is fairly high since they are not specific inhibitors of the proteolytic system in muscle tissue. ${ }^{102}$ Therefore a substance that can specifically block myofibrillar protein degradation in skeletal muscle is still awaiting discovery. The discovery of specific muscle ubiquitin ligases (Atrogin-1 and MuRF1) is particularly interesting since a tissue-specific inhibition of ubiquitin/proteasome proteolysis could be achieved if inhibitors of these ligases were discovered. ${ }^{103}$

\section{Myostatin}

Myostatin, a transforming growth factor beta (TGF- $\beta$ ) superfamily member, has been well characterized as a negative regulator of muscle growth and development. Myostatin has been implicated in several forms of muscle wasting, including the severe cachexia observed as a result of conditions such as AIDS and liver cirrhosis. McFarlane et al have demonstrated that myostatin induces cachexia through an NF- $\mathrm{kB}$-independent mechanism by antagonizing hypertrophy signaling through regulation of the AKT-FoxO1 pathway. ${ }^{104}$ Anti-myostatin strategies are therefore promising and should be considered in future clinical trials involving cachectic patients.

\section{CRF2R agonists}

The corticotropin-releasing factor 2 receptor (CRF2R) has many biological activities including modulation of the stress response and has been involved in the prevention of skeletal muscle wasting that results from a variety of physiological stimuli. Therefore the use of CRF2R agonists has proved successful in partially blocking muscle wasting in several models of experimental cachexia. ${ }^{105,106}$ However, a lack of clinical data exists. 


\section{Conclusion: a multifactorial approache}

From all the data presented, one can speculate that a single therapy may not be the best approach in treating cachexia and treatment regimens involving different combinations are more likely to be successful. Indeed the combination of different nutraceuticals with a high energy diet has led to beneficial effects in experimental animals. ${ }^{107}$ An interesting phase II study, involving the administration of anti-oxidants, pharmaconutritional support, progestagen and anti-cyclooxygenase- 2 drugs, showed both efficacy and safety in the treatment of patients with advanced cancer of different sites suffering from cachexia. Based on the results of the phase II study, a randomized phase III study started in 2005 (and still in progress) includes more than 300 cachectic cancer patients. ${ }^{108}$ These data clearly reinforce the use of these multi-targeted therapies in the treatment of the cachexia-anorexia syndrome in different clinical conditions such as cancer, AIDS and CHF. ${ }^{109}$

\section{References}

1. Evans WJ, Morley JE, Argilés J, et al. Cachexia: a new definition. Clin Nutr. 2008;27(6):793-799.

2. Warren S. The immediate cause of death in cancer. Am J Med Sci. 1932;184:610-613.

3. Mulligan K, Schambelan M. Anabolic treatment with GH, IGF-I, or anabolic steroids in patients with HIV-associated wasting. Int J Cardiol. 2002;85(1):151-159.

4. Anker SD, Sharma R. The syndrome of cardiac cachexia. Int J Cardiol. 2002;85(1):51-66.

5. Argilés JM, Álvarez B, López-Soriano FJ. The metabolic basis of cancer cachexia. Med Res Rev. 1997;17(5):477-498.

6. Argilés JM, López-Soriano FJ. Why do cancer cells have such a high glycolytic rate? Med Hypotheses. 1990;32(2):151-155.

7. Argilés JM, López-Soriano FJ, Busquets S. Mechanisms to explain wasting of muscle and fat in cancer cachexia. Curr Opin Support Palliat Care. 2007;1(4):293-298.

8. Zeisel SH. Regulation of "nutraceuticals". Science. 1999;285(5435): 1853-1855.

9. Ramos EJ, Middleton FA, Laviano A, et al. Effects of omega-3 fatty acid supplementation on tumor-bearing rats. $J$ Am Coll Surg. 2004;199(5):716-723.

10. Argilés JM, López-Soriano FJ, Busquets S. Novel approaches to the treatment of cachexia. Drug Discov Today. 2008;13(1-2):73-78.

11. De Wys W. Working conference on anorexia and cachexia of neoplastic disease. Cancer Res. 1970;30(11):2816-2818.

12. Loprinzi CL, Michalak JC, Schaid DJ, et al. Phase III evaluation of megestrol acetate as therapy for patients with cancer anorexia and/or cachexia. J Clin Oncol. 1993;11(4):762-767.

13. Neri B, Garos VLI, Intini C. Effect of medroxyprogesterone acetate on the quality of life of the oncologic patient: a multicentric cooperative study. Anticancer Drugs. 1997;8(5):459-465.

14. Mccarthy H, Crowder R, Dryden S, Williams G. Megestrol acetate stimulates food and water intake in the rat: effects on regional hypothalamic neuropeptide Y concentrations. Eur J Pharmacol. 1994;265(1-2):99-102.

15. Loprinzi CL, Schaid DJ, Dose AM, Burnham NL, Jensen MD. Bodycomposition changes in patients who gain weight while receiving megestrol acetate. J Clin Oncol. 1993;11(1):152-154.
16. Tomíska M, Tomisková M, Salajka F, Adam Z, Vorlícek J. Palliative treatment of cancer anorexia with oral suspension of megestrol acetate. Neoplasma. 2003;50(3):227-233.

17. Les'niak W, Bała M, Jaeschke R, Krzakowski M. Effects of megestrol acetate in patients with cancer anorexia-cachexia syndrome-a systematic review and meta-analysis. Pol Arch Med Wewn. 2008;118(11): 636-644.

18. Mitchelson F. Pharmacological agents affecting emesis: a review. Drugs. 1992;43(3):295-315.

19. Srivastava MD, Srivastava BI, Brouhard B. Delta9 tetrahydrocannabinol and cannabidiol alter cytokine production by human immune cells. Immunopharmacology. 1998;40(3):179-185.

20. Facchinetti F, Del Giudice E, Furegato S, Passarotto M, Leon A. Cannabinoids ablate release of TNFalpha in rat microglial cells stimulated with lypopolysaccharide. Glia. 2003;41(2):161-168.

21. Strasser F, Luftner D, Possinger K, et al. Comparison of orally administered cannabis extract and delta-9-tetrahydrocannabinol in treating patients with cancer-related anorexia-cachexia syndrome: a multicenter, phase III, randomized, double-blind, placebo controlled clinical trial from the Cannabis-In-Cachexia-Study-Group. J Clin Oncol. 2006;24(21):3394-3400.

22. Rossi-Fanelli F, Cangiano C. Increased availability of tryptophan in brain as a common pathogenic mechanism for anorexia associated with different diseases. Nutrition. 1991;7(5):364-367.

23. Kardinal CG, Loprinzi CL, Schaid DJ, et al. A controlled trial of cyproheptadine in cancer patients with anorexia. Cancer. 1990;65(12): 2657-2662.

24. Couluris M, Mayer JL, Freyer DR, Sandler E, Xu P, Krischer JP. The effect of cyproheptadine hydrochloride (periactin) and megestrol acetate (megace) on weight in children with cancer/treatment-related cachexia. J Pediatr Hematol Oncol. 2008;30(11):791-797.

25. Sarcev T, Secen N, Sabo A, Povazan D. Influence of dexamethasone on appetite and bodyweight in lung cancer patients. Med Pregl. 2008;61(11-12):571-575.

26. Derogatis L, Macdonald R. Psychopharmacologic applications to cancer. Cancer. 1982;50(9):1968-1973.

27. Vigano A, Watanabe S, Bruera E. Anorexia and cachexia in advanced cancer patients. Cancer Surv. 1994;21:99-115.

28. Dixit VD, Schaffer EM, Pyle RS, et al. Ghrelin inhibits leptin- and activation-induced proinflammatory cytokine expression by human monocytes and T cells. J Clin Invest. 2004;114(1):57-66.

29. Nagaya, N Kojima M, Kangawa K. Ghrelin, a novel growth hormonereleasing peptide, in the treatment of cardiopulmonary-associated cachexia. Intern Med. 2006;45(3):127-134.

30. Garcia JM, Polvino WJ. Effect on bodyweight and safety of RC-1291, a novel, orally available ghrelin mimetic and growth hormone secretagogue: results of a phase I, randomized, placebo-controlled, multipledose study in healthy volunteers. Oncologist. 2007;12(5):594-600.

31. Shimizu H, Inoue K, Mori M. The leptin-dependent and -independent melanocortin signaling system: regulation of feeding and energy expenditure. J Endocrinol. 2007;193(1):1-9.

32. Scarlett JM, Marks DL. The use of melanocortin antagonists in cachexia of chronic disease. Expert Opin Investig Drugs. 2005;14(10):1233-1239.

33. Deboer MD, Marks DL. Therapy insight: use of melanocortin antagonists in the treatment of cachexia in chronic disease. Nat Clin Pract Endocrinol Metab. 2006;2(8):459-466.

34. Evans RD, Argilés JM, Williamson DH. Metabolic effects of tumor necrosis factor- $\alpha$ (cachectin) and interleukin-1. Clin Sci. 1989;77(4): 357-364.

35. Yamamoto N, Kawamura I, Nishigaki F, et al. Effect of FR143430, a novel cytokine suppressive agent, on adenocarcinoma colon26-induced cachexia in mice. Anticancer Res. 1998;18(1A):139-144.

36. Balazs C, Kiss E. Immunological aspects of the effect of pentoxifylline (trental). Acta Microbiol Immunol Hung. 1994;41(2):121-126.

37. Goldberg RM, Loprinzi CL, Mailliard JA, et al. Pentoxifylline for treatment of cancer anorexia and cachexia? A randomized, double-blind, placebo-controlled trial. J Clin Oncol. 1995;13(11):2856-2859. 
38. Sampaio EP, Sarno EN, Galilly R, Cohn ZA, Kaplan G. Thalidomide selectively inhibits tumor necrosis factor- $\alpha$ production in stimulated human monocytes. J Exp Med. 1991;173(3):699-703.

39. Sampaio EP, Kaplan G, Miranda A, et al. The influence of thalidomide on the clinical and immunological manifestation of erithema nodosum leprosum. J Infect Dis. 1993;168(2):408-414.

40. Gordon JN, Trebble TM, Ellis RD, Duncan HD, Johns T, Goggin PM. Thalidomide in the treatment of cancer cachexia: a randomised placebo controlled trial. Gut. 2005;54(4):447-448.

41. Carbó N, Costelli P, Tessitore L, et al. Anti-TNF- $\alpha$ treatment interferes with changes in lipid metabolism in a tumor cachexia model. Clin Sci. 1994;87(3):349-355.

42. Costelli P, Carbó N, Tessitore L, et al. TNF- $\alpha$ mediates changes in tissue protein turnover in a rat cancer cachexia model. J Clin Invest 1993;92(6):2783-2789.

43. Jatoi A, Dakhil SR, Nguyen PL, et al. A placebo-controlled double blind trial of etanercept for the cancer anorexia/weight loss syndrome: results from $\mathrm{N} 00 \mathrm{C} 1$ from the North central cancer treatment group. Cancer. 2007;110(6):1396-1403.

44. Yasumoto K, Mukaida N, Harada A, et al. Molecular analysis of the cytokine network involved in cachexia in colon 26 adenocarcinomabearing mice. Cancer Res. 1995;55(4):921-927.

45. Strassmann G, Fong M, Freter CE, Windsor S, D’Alessandro F, Nordan RP. Suramin interfers with interleukin-6 receptor binding in vitro and inhibits colon-26-mediated experimental cancer cachexia in vivo. J Clin Invest. 1993;92(5):2152-2159.

46. Matthys P, Heremans H, Opdenakker G, Billiau A. Anti-interferon- $\gamma$ antibody treatment, growth of Lewis lung tumors in mice and tumorassociated cachexia. Eur J Cancer. 1991;27(2):182-187.

47. Costelli P, Llovera M, Carbó N, García-Martínez C, López-Soriano FJ, Argilés JM. Interleukin-1 receptor antagonist (IL-1ra) is unable to reverse cachexia in rats bearing an ascites hepatoma (Yoshida AH-130). Cancer Lett. 1995;95(1-2):33-38.

48. Monk JP, Phillips G, Waite R, et al. Assessment of TNF- $\alpha$ blockade as an intervention to improve tolerability of dose-intensive chemotherapy in cancer patients. J Clin Oncol. 2006;24(12):1852-1859.

49. Quinn LS, Haugk KL, Grabstein KH. Interleukin-15: a novel anabolic cytokine for skeletal muscle. Endocrinology. 1995;136(8): 3669-3672.

50. Carbó N, López-Soriano J, Costelli P, et al. Interleukin-15 mediates reciprocal regulation of adipose and muscle mass: a potential role in bodyweight control. Biochim Biophys Acta. 2001;1526(1): $17-24$.

51. Figueras M, Busquets S, Carbó N, et al. Interleukin-15 is able to suppress the increased DNA fragmentation associated with muscle wasting in tumor-bearing rats. FEBS Lett. 2004;569(1-3):201-206.

52. Busquets S, Figueras MT, Meijsing S, et al. Interleukin-15 decreases proteolysis in skeletal muscle: a direct effect. Int $J \mathrm{Mol}$ Med. 2005;16(3):471-476.

53. Storer TW, Woodhouse LJ, Sattler F, et al. A randomized, placebocontrolled trial of nandrolone decanoate in human immunodeficiency virus-infected men with mild to moderate weight loss with recombinant human growth hormone as active reference treatment. J Clin Endocrinol Metab. 2005;90(8):4474-4482.

54. Evans W, Smith MR, Morley JE, et al. Ostarine increases lean body mass and improves physical performance in healthy elderly subjects: implications for cancer cachexia patients. ASCO Annual Meeting Proceedings Part I. J Clin Oncol. 2007;25:abstr \#9119.

55. Busquets S, Figueras MT, Fuster G, et al. Anticachectic effects of formoterol: a drug for potential treatment of muscle wasting. Cancer Res. 2004;64(18):6725-6731.

56. Lainscak M, Keber I, Anker SD. Body composition changes in patients with systolic heart failure treated with beta blockers: a pilot study. Int J Cardiol. 2006;106(3):319-322.

57. Rose DP, Connolly JM. Effects of dietary omega-3 fatty acids on human breast cancer growth and metastases in nude mice. J Natl Cancer Inst. 1993;85(21):1743-1747.
58. Tisdale MJ. Mechanism of lipid mobilization associated with cancer cachexia: interaction between the polyunsaturated fatty acid, eicosapentaenoic acid, and inhibitory guanine nucleotideregulatory protein. Prostaglandins Leukot Essent Fatty Acids. 1993; 48(1):105-109.

59. Fearon KC, Von Meyenfeldt MF, Moses AG, et al. Effect of a protein and energy dense N-3 fatty acid enriched oral supplement on loss of weight and lean tissue in cancer cachexia: a randomized double blind trial. Gut. 2003;52(10):1479-1486.

60. Fearon KC, Barber MD, Moses AG. Double-blind, placebo-controlled, randomized study of eicosapentaenoic acid diester in patients with cancer cachexia. J Clin Oncol. 2006;24(21):3401-3407.

61. Dewey A, Baughan C, Dean T, Higgins B, Johnson I. Eicosapentaenoic acid (EPA, an omega-3 fatty acid from fish oils) for the treatment of cancer cachexia. Cochrane Database Syst Rev. 2007;24(1):CD004597.

62. Mehra MR, Lavie CJ, Ventura HO, Milani RV. Fish oils produce antiinflammatory effects and improve bodyweight in severe heart failure. J Heart Lung Transplant. 2006;25(7):834-838.

63. Guarcello M, Riso S, Buosi R, d'Andrea F. EPA-enriched oral nutritional support in patients with lung cancer: effects on nutritional status and quality of life. Nutr Ther and Metab. 2006;24:168-175.

64. Read JA, Beale PJ, Volker DH, Smith N, Childs A, Clarke SJ. Nutrition intervention using an eicosapentaenoic acid (EPA)-containing supplement in patients with advanced colorectal cancer. Effects on nutritional and inflammatory status: a phase II trial. Support Care Cancer. 2007;15(3):301-307.

65. Van der Meij BS, Languis JA, Van Adrichem V, Spreeuwenberg MD, Smit EF, Van Leeuwen PA. A double blind randomized controlled trial on oral nutritional supplementation of omega-3 fatty acids in non-small cell lung carcinoma. Clin Nutr Suppl. 2008;3:111.

66. Bayram I, Erbey F, Celik N, Nelson JL, Tanyeli A. The use of a protein and energy dense eicosapentaenoic acid containing supplement for malignancy-related weight loss in children. Pediatr Blood Cancer. 2009;52(5):571-574.

67. Ryan AM, Reynolds JV, Healy L, et al. Enteral nutrition enriched with eicosapentaenoic acid (EPA) preserves lean body mass following esophageal cancer surgery: results of a double-blinded randomized controlled trial. Ann Surg. 2009;249(3):355-363.

68. Cerchietti LC, Navigante AH, Castro MA. Effects of eicosapentaenoic and docosahexaenoic n-3 fatty acids from fish oil and preferential Cox-2 inhibition on systemic syndromes in patients with advanced lung cancer. Nutr Cancer. 2007;59(1):14-20.

69. De Wys WD. Management of cancer cachexia. Semin Oncol. 1985; 12(4):452-460.

70. Tayek JA, Bistrian BR, Hehir DJ, Martin R, Moldawer LL, Blackburn GL. Improved protein kinetics and albumin synthesis by branched-chain amino acid-enriched total parenteral nutrition in cancer cachexia. Cancer. 1986;58(1):147-157.

71. Hunter DC, Weintraub M, Blackburn GL, Bistrian BR. Branched-chain amino acids as the protein component of parenteral nutrition in cancer cachexia. Br J Surg. 1989;76(2):149-153.

72. Cangiano C, Laviano A, Meguid MM, et al. Effects of administration of oral branched-chain amino acids on anorexia and caloric intake in cancer patients. J Natl Cancer Inst. 1996;88(8):550-552.

73. Busquets S, Álvarez B, López-Soriano FJ, Argilés JM. Branched-chain amino acids: a role in skeletal muscle proteolysis in catabolic states? J Cell Physiol. 2002;191(3):283-289.

74. Meguid MM, Muscaritoli M, Beverly JL, Yang ZJ, Cangiano C, Rossi-Fanelli F. The early cancer anorexia paradigm: changes in plasma free tryptophan and feeding indexes. J Parent Enteral Nutr. 1992;16(6): S56-S59.

75. Fernstrom JD. Dietary effects on brain serotonin synthesis: relationship to appetite regulation. Am J Clin Nutr. 1985;42(5):1072-1082.

76. Souba WW. Glutamine and cancer. Ann Surg. 1993;218(6):715-728.

77. Rivera S, Azcón-Bieto J, López-Soriano FJ, Miralpeix M, Argilés JM. Amino acid metabolism in tumor-bearing mice. Biochem J. 1988; 249(2):443-449. 
78. Chen MK, Salloum RM, Austgen TR, et al. Tumor regulation of hepatic glutamine metabolism. J Parent Enteral Nutr. 1991;15(2):159-164.

79. Ziegler TR, Young LS, Benfell K, et al. Clinical and metabolic efficacy of glutamine-supplemented parenteral nutrition after bone marrow transplantation. Ann Intern Med. 1992;116(10):821-828.

80. Klimberg VS, Nwokedi E, Hutchins LF, et al. Glutamine facilitates chemotherapy while reducing toxicity. J Parent Enteral Nutr. 1992;16(6): S83-S87.

81. Laviano A, Renvyle T, Yang ZJ. From laboratory to bedside: new strategies in the treatment of malnutrition in cancer patients. Nutrition. 1996;12(2):112-122.

82. May PE, Barber A, D'Olimpio JT, Hourihane A, Abumrad NN. Reversal of cancer-related wasting using oral supplementation with a combination of beta-hydroxy-beta-methylbutyrate, arginine, and glutamine. Am J Surg. 2002;183(4):471-479.

83. Dröge W, Gross A, Hack V, et al. Role of cysteine and glutathione in HIV infection and cancer cachexia: therapeutic intervention with N-acetylcysteine. Adv Pharmacol. 1997;38:581-600.

84. Hack V, Gross A, Kinscherf R, et al. Abnormal glutathione and sulfate levels after interleukin-6 treatment in tumor-induced cachexia. FASEB J. 1996;10(10):1219-1226.

85. Kikawa Y, Narumiya S, Fukushima M, Wakatsuka H, Hayaishi O. 9-Deoxy-delta 9, delta 12-13,14-dihydroprostaglandin D2, a metabolite of prostaglandin D2 formed in human plasma. Proc Natl Acad Sci US A. 1984;81(5):1317-1321.

86. Fischer SM, Furstenberger G, Marks F, Slaga TJ. Events associated with mouse skin tumor promotion with respect to arachidonic acid metabolism: a comparison between SENCAR and NMRI mice. Cancer Res. 1987;47(12):3174-3179.

87. Williams ED, Karim SMM, Sandler M. Prostaglandin secretion by medullary carcinoma of the thyroid. A possible cause of the associated diarrhoea. Lancet. 1968;1(7532):22-23.

88. Homem-de-Bittencourt Junior PI, Pontieri V, Curi RR, Lopes OU. Effects of aspirin-like drugs on Walker 256 tumor growth and cachexia in rats. Braz. J Med Biol Res. 1989;22(8):1039-1042.

89. Mccarthy DO, Daun JM. The effects of cyclooxigenase inhibitors on tumor-induced anorexia in rats. Cancer. 1993;71(2):486-492.

90. Hussey HJ, Tisdale MJ. Effect of the specific cyclooxygenase-2 inhibitor meloxicam on tumor growth and cachexia in a murine model. Int $J$ Cancer. 2000;87(1):95-100.

91. Lai V, George J, Richey L, et al. Results of a pilot study of the effects of celecoxib on cancer cachexia in patients with cancer of the head, neck, and gastrointestinal tract. Head Neck. 2008;30(1):67-74.

92. Cahlin C, Gelin J, Delbro D, Lonnroth C, Doi C, Lundholm K. Effect of cyclooxygenase and nitric oxide synthase inhibitors on tumor growth in mouse tumor models with and without cancer cachexia related to prostanoids. Cancer Res. 2000;60(6):1742-1749.

93. Anker SD, Negassa A, Coats AJ, et al. Prognostic importance of weight loss in chronic heart failure and the effect of treatment with angiotensin-converting-enzyme inhibitors: an observational study. Lancet. 2003;361(9363):1077-1083.

94. Adigun AQ, Ajayi AA. The effects of enalapril-digoxin-diuretic combination therapy on nutritional and anthropometric indices in chronic congestive heart failure: preliminary findings in cardiac cachexia. Eur J Heart Fail. 2001;3(3):359-363.
95. Zhao SP, Xie XM. Captopril inhibits the production of tumor necrosis factor-alpha by human mononuclear cells in patients with congestive heart failure. Clin Chim Acta. 2001;304(1-2):85-90.

96. Sanders PM, Russell ST, Tisdale MJ. Angiotensin II directly induces muscle protein catabolism through the ubiquitin-proteasome proteolytic pathway and may play a role in cancer cachexia. $B r J$ Cancer. 2005;93(4):425-434.

97. Lindholm E, Daneryd P, Körner U, Hyltander A, Fouladiun M, Lundholm K. Effects of recombinant erythropoietin in palliative treatment of unselected cancer patients. Clin Cancer Res. 2004;10(20): 6855-6864.

98. Kanzaki M, Soda K, Gin PT, Kai T, Konishi F, Kawakami M. Erythropoietin attenuates cachectic events and decreases production of interleukin-6, a cachexia-inducing cytokine. Cytokine. 2005; 32(5):234-239.

99. Agteresch HJ, Dagnelie PC, Van der Gaast A, Stijnen T, Wilson JH. Randomized clinical trial of adenosine $5^{\prime}$-triphosphate in patients with advanced non-small-cell lung cancer. $J$ Natl Cancer Inst. 2000; 92(4):321-328.

100. Agteresch HJ, Rietveld T, Kerkhofs LG, Van den Berg JW, Wilson JH, Dagnelie PC. Beneficial effects of adenosine triphosphate on nutritional status in advanced lung cancer patients: a randomized clinical trial. J Clin Oncol. 2002;20(2):371-378.

101. Lee DH, Goldberg AL. Proteasome inhibitors: valuable new tools for cell biologists. Trends Cell Biol. 1998;8(10):397-403.

102. von Haehling S, Genth-Zotz S, Anker SD, Volk HD. Cachexia: a therapeutic approach beyond cytokine antagonism. Int $J$ Cardiol. 2002;85(1):173-183.

103. Bodine SC, Latres E, Baumhueter S, et al. Identification of ubiquitin ligases required for skeletal muscle atrophy. Science. 2001;294(5547): 1704-1708.

104. McFarlane C, Plummer E, Thomas M, et al. Myostatin induces cachexia by activating the ubiquitin proteolytic system through an NF-KB-independent, FoxO1-dependent mechanism. J Cell Physiol. 2006;209(2):501-514.

105. Isfort RJ, Wang F, Tscheiner M, et al. Discovery of corticotropin releasing factor 2 receptor selective sauvagine analogues for treatment of skeletal muscle atrophy. $J$ Med Chem. 2005;48(1):262-265.

106. Argilés JM, Figueras M, Ametller E, et al. Effects of CRF2R agonist on tumor growth and cachexia in mice bearing the Lewis lung carcinoma. Muscle Nerve. 2008;37(2):190-195.

107. van Norren K, Kegler D, Argilés JM, et al. Dietary supplementation with a specific combination of high protein, leucine, and fish oil improves muscle function and daily activity in tumor-bearing cachectic mice. Br J Cancer. 2009;100(5):713-722.

108. Mantovani G, Macciò A, Madeddu C, et al. A phase II study showing efficacy and safety in patients with cancer-related anorexia/ cachexia and oxidative stress. Cancer Epidemiol Biomarkers Prev. 2006;15(5):1030-1034.

109. Argilés JM, Almendro V, Busquets S, López-Soriano FJ. The pharmacological treatment of cachexia. Curr Drug Targets. 2004;5(3): 265-277.
Cancer Management and Research

\section{Publish your work in this journal}

Cancer Management and Research is an international, peer-reviewed open access journal focusing on cancer research and the optimal use of preventative and integrated treatment interventions to achieve improved outcomes, enhanced survival and quality of life for the cancer patient. The journal welcomes original research, clinical \& epidemiological

\section{Dovepress}

studies, reviews \& evaluations, guidelines, expert opinion \& commentary, case reports \& extended reports. The manuscript management system is completely online and includes a very quick and fair peerreview system, which is all easy to use. Visit http://www.dovepress.com/ testimonials.php to read real quotes from published authors. 